\title{
The contribution of the rs55705857 G allele to familial cancer risk as estimated in the Utah population database
}

\author{
Sarah Hummel ${ }^{5^{*}}$ (D), Wendy Kohlmann ${ }^{7}$, Thomas M. Kollmeyer ${ }^{6}$, Robert Jenkins ${ }^{6}$, Joshua Sonnen ${ }^{8}$, Cheryl A. Palmer ${ }^{8}$,
} Howard Colman ${ }^{4}$, Diana Abbott ${ }^{2}$, Lisa Cannon-Albright ${ }^{1,2}$ and Adam L. Cohen ${ }^{3}$

\begin{abstract}
Background: IDH1/2 mutated glioma has been associated with a germline risk variant, the rs55705857 G allele. The Utah Population Database (UPDB), a computerized genealogy of people in Utah, is a unique resource to evaluate cancer risk in related individuals.

Methods: One hundred and two individuals with IDH1/2 mutant or 1p/19q co-deleted glioma were genotyped and linked to the UPDB. DNA came from blood (21), tumor tissue (43), or both (38). We determined congruence between somatic and germline samples and estimated the relative risk for developing cancer to first and seconddegree relatives of $\mathrm{G}$ and $\mathrm{A}$ allele carriers at rs55705857.

Results: Somatic (glioma) DNA had $85.7 \%$ sensitivity (Cl 57.2-98.2\%) and 95.8\% specificity (Cl 78.9-99.89\%) for germline rs55705857 G allele. Forty-one patients were linked to pedigrees in the UPDB with at least three generations of data. First-degree relatives of rs55705857 G allele carriers were at significantly increased risk for developing cancer ( $\mathrm{RR}=1.72, p=0.045, \mathrm{Cl} 1.02-2.94)$, and specifically for oligodendroglioma $(\mathrm{RR}=57.61, p=0.017$, $\mathrm{Cl}$ 2.96-320.98) or prostate cancer ( $\mathrm{RR}=4.10, p=0.008, \mathrm{Cl} 1.62-9.58$ ); relatives of individuals without the $\mathrm{G}$ allele were not at increased risk. Second-degree relatives of $\mathrm{G}$ allele carriers also had significantly increased risk for developing cancer ( $R R=1.50, p=0.007, \mathrm{Cl} 1.15-2.01)$.

Conclusions: Tumor DNA may approximate genotype at the rs55705857 locus. We confirmed this locus confers an increased risk of all cancers and especially of oligodendroglioma. No increased cancer or brain tumor risk is seen in family members of individuals without the high-risk $\mathrm{G}$ allele.
\end{abstract}

Keywords: Molecular epidemiology, IDH, rs55705857, Oligodendroglioma, Cancer

\section{Background}

Germline genetic testing is a powerful tool that can yield important predictive information about a person's future health [1-3]. Detection of germline pathogenic mutations can lead to improved screening, additional prevention strategies, and better understanding of personal cancer risk [1-3]. Gliomas are categorized by somatic genetic/molecular profiling in addition to histology in order to improve treatment targets or provide

\footnotetext{
* Correspondence: sarah.hummel1@va.gov

${ }^{5}$ Department of Human Genetics/Pediatric Division of Medical Genetics, Graduate Program in Genetic Counseling, University of Utah School of Medicine, 15 North 2030 East, Salt Lake City 84112, Utah, USA

Full list of author information is available at the end of the article
}

prognostic information [3-6]. Germline genetic associations with specific somatic molecular subtypes are just beginning to be understood $[2-4,6,7]$.

Glioma is the most common type of primary brain cancer, with an overall glioma incidence of approximately 5 per 100,000 persons per year [8]. Gliomas are now characterized based on the presence of mutations in the isocitrate dehydrogenase family of genes (IDH1 and IDH2) [6]. Mutations in $I D H 1$ or $I D H 2$ are found in $100 \%$ of oligodendrogliomas, $70-80 \%$ of lower grade astrocytomas, and in secondary glioblastoma [9]. Co-deletion of chromosomes $1 \mathrm{p}$ and 19q can be used as a surrogate for $I D H \mathrm{mu}-$ tation because $1 \mathrm{p} / 19 \mathrm{q}$ co-deletion is invariably associated with $I D H$ mutation [10].

(c) The Author(s). 2019 Open Access This article is distributed under the terms of the Creative Commons Attribution 4.0 International License (http://creativecommons.org/licenses/by/4.0/), which permits unrestricted use, distribution, and reproduction in any medium, provided you give appropriate credit to the original author(s) and the source, provide a link to the Creative Commons license, and indicate if changes were made. The Creative Commons Public Domain Dedication waiver (http://creativecommons.org/publicdomain/zero/1.0/) applies to the data made available in this article, unless otherwise stated. 
Many studies have found genetic contributions to familial glioma risk ( $R R \sim 2.0-3.8)$, but the original studies were unable to identify the origin of the increased risk [11, 12]. Recently, genome wide association studies have consistently identified the rs55705857 $\mathrm{G}$ allele at $8 \mathrm{q} 24$ as a risk factor for gliomagenesis that is specific for IDH1/2 mutated gliomas [5, 7, 13-18]. Approximately 40\% of individuals with IDH1/2 mutated oligodendrogliomas and astrocytomas carry the germline rs55705857 G allele, compared with approximately $8 \%$ of the general population $[5,13]$. The identification of rs55705857 $\mathrm{G}$ allele as a contributing factor to glioma development specific for IDH mutated gliomas provides an opportunity to more precisely calculate risks to relatives of patients with glioma.

All prior studies of risk alleles have been case-control or GWAS studies. We explore the heritability of glioma associated with the rs55705857 $\mathrm{G}$ allele in a population based cohort database. We used the Utah Population Database (UPDB), a computerized resource that links data from the Utah Cancer Registry, Utah birth and death certificates, and Utah driver licenses, among other data sources. Over 6.5 million individuals have data linked to the UPDB computerized resource. Data available from the Utah Cancer registry, a Surveillance, Epidemiology and End Results registry, spans from 1973 to 2012 and includes primary site, histology, age at diagnosis, stage, grade, survival, and treatment data. Over 2.5 million individuals have at least three generations of genealogy data that connects to the original Utah genealogy [19]. The UPDB resource allowed us to evaluate the association between the rs55705857 $\mathrm{G}$ allele and several types of $I D H$ associated cancers in relatives of individuals with $I D H 1 / 2$ mutated glioma.

We hypothesized that first and second-degree relatives of patients with an $I D H 1 / 2$ mutated glioma and a germline rs55705857 $\mathrm{G}$ allele had higher risk for developing one or more of the following cancers in which $I D H 1 / 2$ mutations have been found: glioma, prostate, colon, hepatic, lymphomas, biliary tumors, primary myelofibrosis, central chondrosarcoma, chrondroma/enchondroma, thyroid, acute lymphoblastic leukemia, and acute myelogenous leukemia [20-22]. We also aimed to determine the accuracy of tumor tissue for assessing the rs55705857 G allele and the relative risk of specific cancers in first and second-degree relatives of individuals with IDH1/2 mutated gliomas with and without the rs55705857 G allele.

\section{Methods}

\section{Patient identification/Proband sample population}

The population of this study was derived from the Huntsman Cancer Institute Cancer Clinical Research Database (CCR). Secondary analyses of patient data and specimens with a waiver of informed consent were approved by the University of Utah IRB and all research was conducted following the international standards set forth in the Declaration of Helsinki. Patients were identified using CPT and ICD-9 codes for histology and location to find Grade II-III oligodendroglioma, oligoastrocytoma, glioma NOS, and/or astrocytoma patients, and only individuals with tumors with documented IDH1 mutations, IDH 2 mutations, or $1 \mathrm{p} / 19 \mathrm{q}$ codeletion were included. Stored germline tissues, somatic tissues, or DNA was obtained from the HCI Biorepository. In total, 102 unique patients had DNA or tissue samples available and were genotyped for the G allele of rs55705857 SNP (Table 1).

\section{Genotyping}

$\mathrm{G}$ allele genotyping at rs55705857 was performed by the Mayo Clinic Genotyping Core, utilizing a TaqMan Assay from ABI with Genotyping Master Mix. Amplification and post amplification genotype readings were performed on an Applied Biosystems HT7900. Samples were submitted in 96-well plates. Fifteen water blanks and replicate samples were plated at random.

We considered the patient to be germline positive for the rs55705857 $\mathrm{G}$ allele when at least one replicate of the sample had complete agreement with two runs detecting heterozygote/homozygote status for the $\mathrm{G}$ allele. Somatic DNA was considered positive for detection of the rs55705857 $\mathrm{G}$ allele when one of the two runs detected the $\mathrm{G}$ allele (Additional file 1: Table S1).

\section{Linking records to the UPDB}

The Utah population is predominantly of Northern European ancestry with average rates of consanguinity similar to those for the United States and negligible genetic drift $[23,24]$. We linked patients meeting our study criteria to the UPDB; after linkage, no identifiers were used. Record linkage and analyses were approved by The University of Utah Institutional Review Board and the Resource for Genetic Epidemiologic Research. There was no contact with human subjects. Familial cancer risk analyses were only performed on patients with at least three generations of genealogy.

Table 1 DNA sample characteristics of glioma patients harboring IDH1/2 mutant or 1p/19q co-deletion

\begin{tabular}{lll}
\hline DNA Source & Male Patients & Female Patients \\
\hline Somatic & 15 & 28 \\
Germline & 10 & 11 \\
Somatic and Germline & 21 & 17 \\
\hline
\end{tabular}

Somatic DNA was derived from tumor samples. Germline DNA was derived from blood samples. One hundred and two individuals had one or more sources of DNA available for analysis 


\section{Analysis}

Methods used to analyze genealogical data within the UPDB have been previously described in detail [11, 19, 25]. Our work estimated the Relative Risk (RR) of cancer in first and second-degree relatives of genotyped patients. The RR of cancer in relatives of genotyped patients is defined as the ratio of the observed number of cancers for a given set of relatives to the expected number of cancers. Expected numbers of cancers are based on cohort-specific population rates for each cancer, calculated from within the UPDB. Cohorts represent sex, birth state (Utah or not), and 5-year birth-year groups. The expected number of relatives with cancer was estimated by counting all relatives of the genotyped patients by cohort, then multiplying the number of relatives in a given cohort by the cohort-specific rate of each tumor subtype. That value was summed over all cohorts to create estimates of the RR for each cancer. Given a null hypothesis $R R \leq 1$, we calculated one-sided probabilities that RR $>1$. We assumed the number of observed cancers followed a Poisson random variable with a mean equal to the expected number of cases.

\section{Results}

Presence or absence of the rs55705857 G allele was successfully determined for one hundred two individuals (Table 1). We determined congruence between somatic and germline DNA for 38 of 102 (37\%) individuals. We assumed DNA derived from blood or other non-tumor tissue was an accurate representation of germline DNA complement. Somatic (glioma) DNA had 85.7\% Sensitivity (CI 57.2-98.2\%) and 95.8\% Specificity (CI 78.999.89\%) for predicting the presence of the rs55705857 G allele in the germline. Somatic DNA had a positive predictive value (PPV) of 93.2\% (CI 90.1-94.0\%) and 90.9\% negative predictive value (CI 89.2-91.3\%). The overall accuracy of tumor genotype was $92.1 \%$ (CI 78.6-98.3\%) (Fig. 1). Germline DNA was not available for all

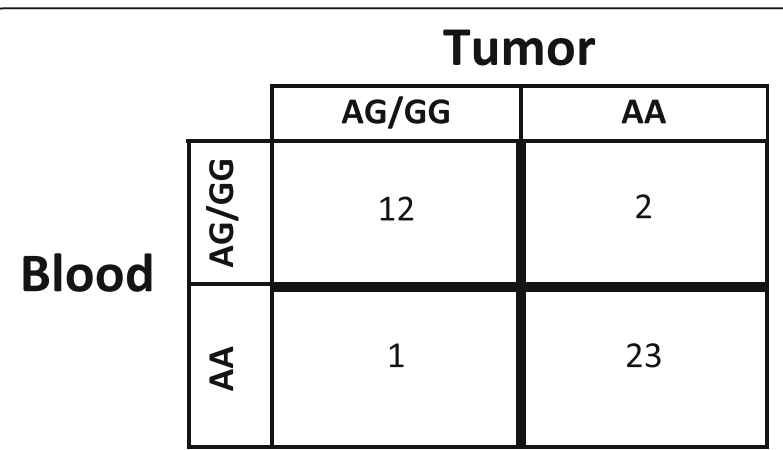

Fig. 1 Accuracy of genotype in 38 individuals with somatic and germline DNA samples. Abbreviations: AA, rs55705857 A allele homozygote; AG, rs55705857 G allele heterozygote; GG, rs55705857 $G$ allele homozygote. Calculations assume that DNA derived from blood is the true germline representation of the individual participants. Based on the high rate of concordance between the germline and somatic rs55705857 genotype, germline genotypes were inferred for those without germline DNA based on the somatic genotype.

Of the 102 genotyped individuals, forty-one individuals were linked to $\geq 3$ generation UPDB genealogies. Eighteen of 41 subjects were found to have the rs55705857 G allele ( $\mathrm{G}$ allele carriers). The $\mathrm{G}$ allele carriers had 140 first-degree relatives in UPDB; 13 cancers were observed in that population. The $G$ allele carriers had $412 \mathrm{~s}$-degree relatives with 44 cancers. Relative risk estimates for a subset of cancers are summarized in Table 2.

First-degree relatives of $\mathrm{G}$ allele carriers were at significantly increased risks for developing any cancer (RR $=1.72, p=0.045$, CI 1.02-2.94) and specifically for developing oligodendroglioma $(\mathrm{RR}=57.61, \quad p=0.017, \quad \mathrm{CI}$ $2.96-320.98)$ or prostate cancer $(\mathrm{RR}=4.10, p=0.008, \mathrm{CI}$ 1.62-9.58). Conversely, first-degree relatives of individuals who did not carry the high-risk $G$ allele (rs55705857 A allele homozygotes) were not at significantly increased risk for developing cancer overall, or for developing any individual cancer tested (Table 3).

Second-degree relatives of $G$ allele carriers had an overall significantly increased risk for developing cancer $(\mathrm{RR}=1.50, p=0.007, \mathrm{CI} 1.15-2.01)$, and specifically for developing colorectal cancer $(\mathrm{RR}=2.21, p=0.043$, CI 1.04-4.55) (Table 4).

Again, no increased cancer risk was seen in second-degree relatives of rs55705857 A allele homozygote individuals (Table 5).

\section{Discussion}

We report a novel association between the rs55705857 G allele and multiple cancers. It is possible that this risk allele is not responsible for these cancers and that instead cosegregation between the rs55705857 G allele and one or more risk-associated single-nucleotide-polymorphisms in $8 \mathrm{q} 24$ is responsible for the excess prostate and colon

Table 2 Cancer incidence for 1 st degree relatives of $\mathrm{G}$ allele carriers

\begin{tabular}{llllll}
\hline Cancer Type & Obs & Exp & 1 T P-Value & RR & $95 \% \mathrm{Cl}$ \\
\hline ANY CANCER & 13 & 7.56 & 0.045 & 1.72 & $1.02-2.94$ \\
BRAIN & $\leq 5$ & $*$ & 0.163 & 5.61 & $0.29-31.24$ \\
- OLIGODENDROGLIOMA & $\leq 5$ & $*$ & 0.017 & 57.61 & $2.96-320.98$ \\
COLORECTAL & $\leq 5$ & $*$ & 0.546 & 0 & $0-4.95$ \\
THYROID & $\leq 5$ & $*$ & 0.750 & 0 & $0-10.43$ \\
PROSTATE & $\leq 5$ & $*$ & 0.008 & 4.1 & $1.62-9.58$ \\
\hline
\end{tabular}

Abbreviations: Obs observed number of individuals with given cancer, Exp expected number of individuals with given cancer, $1 T P$-Value one-tailed $p$-value, $R R$ relative risk, $\mathrm{Cl}$ confidence interval

For all cancer sites with $\leq 5$ observed cases, exact values are not shown for observed and expected to preserve patient anonymity per the Utah Resource for Genetic and Epidemiologic Research (RGE) requirements and are marked with an asterisk. Cancer incidence calculated in one hundred forty first-degree relatives 
Table 3 Cancer incidence for 1 st degree relatives of rs55705857 A allele homozygote individuals

\begin{tabular}{llllll}
\hline Cancer Type & Obs & Exp & 1 T P-Value & RR & $95 \% \mathrm{Cl}$ \\
\hline ANY CANCER & 12 & 11.91 & 0.528 & 1.01 & $0.58-1.76$ \\
BRAIN & $\leq 5$ & $*$ & 0.772 & 0 & $0-11.58$ \\
- OLIGODENDROGLIOMA & $\leq 5$ & $*$ & 0.976 & 0 & $0-124.9$ \\
COLORECTAL & $\leq 5$ & $*$ & 0.260 & 2.02 & $0.36-7.3$ \\
THYROID & $\leq 5$ & $*$ & 0.665 & 0 & $0-7.35$ \\
PROSTATE & $\leq 5$ & $*$ & 0.097 & 0 & $0-1.28$
\end{tabular}

Abbreviations: Obs observed number of individuals with given cancer, Exp expected number of individuals with given cancer, $1 T$ P-Value one-tailed $p$-value, $R R$ relative risk, $\mathrm{Cl}$ confidence interval

For all cancer sites with $\leq 5$ observed cases, exact values are not shown for observed and expected to preserve patient anonymity per the Utah Resource for Genetic and Epidemiologic Research (RGE) requirements and are marked with an asterisk. Cancer incidence calculated in one hundred and seventy-six first-degree relatives

cancer in our patient's families [26-30]. However, studying a population of individuals with rare cancers and extended family history data may have allowed us to detect an association missed by previous GWAS and whole genome-sequencing studies [26-30]. Given that screening recommendations for prostate and colon cancer in high risk populations already exist, confirmation of this possibility in larger studies is warranted.

The ability to use tumor DNA for germline genotypes greatly expands the population available for familiality studies involving the 8q24 region. With tumor DNA, there is always a concern that somatic mutations or deletions will mask accurate genotypes and that tumor genotype may change over time [3,31]. The confidence intervals on our results suggest that that the accuracy of tumor DNA from initial surgeries for genotype analysis of the rs55705857 $\mathrm{G}$ allele in tumor is at least $~ 80 \%$. Our result of high accuracy in $8 \mathrm{q} 24$ tumor DNA is in line with previous literature indicating that this region may contain gliomagenesis driver mutations that are

Table 4 Cancer incidence for 2 nd degree relatives of $\mathrm{G}$ allele carriers

\begin{tabular}{llllll}
\hline Cancer Type & Obs & Exp & 1 T P-Value & RR & $95 \% \mathrm{Cl}$ \\
\hline ANY CANCER & 44 & 29.4 & 0.007 & 1.5 & $1.15-2.01$ \\
BRAIN & $\leq 5$ & $*$ & 0.603 & 0 & $0-5.92$ \\
- OLIGODENDROGLIOMA & $\leq 5$ & $*$ & 0.972 & 0 & $0-106.05$ \\
COLORECTAL & 7 & 3.17 & 0.043 & 2.21 & $1.04-4.55$ \\
THYROID & $\leq 5$ & $*$ & 0.114 & 3.48 & $0.62-12.56$ \\
PROSTATE & 7 & 6.2 & 0.426 & 1.13 & $0.53-2.33$
\end{tabular}

Abbreviations: Obs observed number of individuals with given cancer, Exp expected number of individuals with given cancer, $1 T P$-Value one-tailed $p$-value; $R R$ relative risk, $C l$ confidence interval

For all cancer sites with $\leq 5$ observed cases, exact values are not shown for observed and expected to preserve patient anonymity per the Utah Resource for Genetic and Epidemiologic Research (RGE) requirements and are marked with an asterisk. Cancer incidence calculated in four hundred and twelve second-degree relatives
Table 5 Cancer incidence for 2nd degree relatives of rs55705857 A allele homozygote individuals

\begin{tabular}{llllll}
\hline Cancer Type & Obs & Exp & 1 T P-Value & RR & $95 \% \mathrm{Cl}$ \\
\hline ANY CANCER & 43 & 34.73 & 0.097 & 1.24 & $0.94-1.67$ \\
BRAIN & $\leq 5$ & $*$ & 0.569 & 0 & $0-5.31$ \\
- OLIGODENDROGLIOMA & $\leq 5$ & $*$ & 0.970 & 0 & $0-97.08$ \\
COLORECTAL & $\leq 5$ & $*$ & 0.338 & 1.31 & $0.51-3.05$ \\
THYROID & $\leq 5$ & $*$ & 0.554 & 0 & $0-5.07$ \\
PROSTATE & 8 & 7.87 & 0.529 & 1.02 & $0.51-2.00$
\end{tabular}

Abbreviations: Obs observed number of individuals with given cancer, Exp expected number of individuals with given cancer, $1 T P$-Value one-tailed $p$-value, $R R$ relative risk, $\mathrm{Cl}$ confidence interval

For all cancer sites with $\leq 5$ observed cases, exact values are not shown for observed and expected to preserve patient anonymity per the Utah Resource for Genetic and Epidemiologic Research (RGE) requirements and are marked with an asterisk. Cancer incidence calculated in four hundred and thirty-six second-degree relatives

preserved and rarely deleted in gliomas [5]. Our results cannot assess whether tumor genomic evolution would affect this accuracy in tumor samples from reresection after chemotherapy and/or radiation.

Limitations of this study include the rarity of glioma in the general population and small number of tissue samples available in the CCR, which leads to large confidence intervals. Data censoring is present due to 61 samples failing to link to genealogy data and lack of data on cancers treated outside of Utah or diagnosed before 1966. However, from previous studies the number of such cancers is expected to be low [25]. Selection bias due to unknown confounders may be present but clinical factors such as age were not significantly different between individuals linked to genealogy data and those unlinked. Confirmation of our findings in other independent datasets is needed to validate our findings and refine risk estimates.

Although we expect $50 \%$ of first-degree relatives of G allele carriers to carry the $G$ allele, first and second-degree relatives were not genotyped, which might have diluted the results for association between a high-risk allele and cancer incidence. It is possible that the risk of cancer in people who carry the $G$ allele and who have a first degree relative with an $I D H$ mutated glioma is twice as high as estimated. Greater sample size is needed to confirm these preliminary results.

\section{Conclusion}

This was the first epidemiological study estimating cancer risks among first and second-degree relatives of rs55705857 G allele carriers [32]. Our population-based analysis confirms and extends previously published results associating the rs55705857 $\mathrm{G}$ allele with $I D H \mathrm{mu}$ tated gliomas [5, 13, 15, 32-34]. We provide the first evidence in a prospectively identified cohort of this association. 
We showed for the first time that relatives of rs55705857 G allele carriers have an increased risk of any cancer and especially of oligodendrogliomas, while relatives of A allele homozygote carriers had no increased risk of any cancer. A link between the $\mathrm{G}$ allele of rs55705857 and both prostate and colon cancer was suggested, but these results should be confirmed in an independent population $[26,27]$. This manuscript provides evidence that allele status at rs55705857 is stable in tumors, confirms an increased risk of oligodendroglioma in first-degree relatives of rs55705857 G allele carriers, and suggests that further study of the role of the G allele in other cancers is warranted. Future work identifying the cancer risk based on relatives' genotype and on identifying the $I D H$ status in non-gliomas associated with the rs55705857 $\mathrm{G}$ allele is warranted.

\section{Additional file}

\section{Additional file 1: Table S1: DNA sample characteristics of glioma} patients harboring IDHI/2 mutant or $1 \mathrm{p} / 19 \mathrm{q}$ co-deletion. Legend: Shown are the genotype results of 102 unique individuals. Samples were submitted in 96-well plates. Fifteen water blanks and replicate samples were plated at random. Cells highlighted in blue were called G Allele positive for rs55705857. Cells highlighted in orange have discrepancy between $\mathrm{G}$ allele status at rs55705857 in blood and tumor samples. Blood is germline and thus was held to be the true representation of an individual's $\mathrm{G}$ allele status at rs55705857. (PDF $315 \mathrm{~kb}$ )

\section{Abbreviations \\ 1 T $P$-Value: one-tailed $p$-value; CCR: Huntsman cancer institute cancer clinical research database; $\mathrm{Cl}$ : confidence interval confidence interval; Exp: expected number of individuals with given cancer; $\mathrm{HCl}$ : Huntsman cancer institute; IDH: Isocitrate dehydrogenase family of genes; IRB: Institutional review board; Obs: observed number of individuals with given cancer; RGE: The Utah resource for genetic and epidemiologic research; RR: relative risk; \\ SEER: Surveillance, epidemiology and end results; UCR: Utah cancer registry; UPDB: The Utah population database}

\section{Acknowledgements}

Adam Cohen acknowledges the inspiration of Jessica Jennifer Cohen. We would like to thank the Division of Genetic Epidemiology at the University of Utah for their guidance and support throughout this project. Special thanks to Robert Jenkins and Tom Kollmeyer at the Mayo Clinic for their invaluable work genotyping patient samples. We gratefully acknowledge the NeuroOncology Disease-Oriented Team for its support, and the Huntsman Cancer Institute $(\mathrm{HCl})$ and the generous donors to the Huntsman Cancer Foundation without whom, this work would not have been possible. We also acknowledge the individual patients who provided the biospecimens utilized for this research, as well as the $\mathrm{HCl}$ Biorepository, which is a CAP accredited resource that coordinates biospecimen processing, storing and distributing high quality biospecimens. This work has been presented previously in poster format at the 2016 National Society of Genetic Counselors Annual Education Conference (Poster \#C-354, Abstract DOI https://doi.org/10.1007/ s10897-016-0027-x) and as an oral presentation at the 2016 Society for NeuroOncology Annual Scientific Meeting (Abstract \#EPID-11).

\section{Funding}

Research was supported by the Utah Cancer Registry, which is funded by Contract No. HHSN261201300017l from the National Cancer Institute's SEER program with additional support from the Utah State Department of Health and the University of Utah. Partial support for all data sets within the Utah Population Database (UPDB) and use of the Genetic Counseling Shared Resource was provided by Huntsman Cancer Institute, Huntsman Cancer
Foundation, University of Utah, and the Huntsman Cancer Institute's Cancer Center Support grant, P30CA42014 from the National Cancer Institute of the National Institutes of Health. Resources of the neuro-oncology Disease-Oriented Team and the $\mathrm{HCl}$ Biorepository are supported the Huntsman Cancer Institute Cancer Center Support Grant (P30CA042014). The content is solely the responsibility of the authors and does not necessarily represent the official views of the NIH. Additional funding was provided by the Pediatrics Division of Medical Genetics at the University of Utah, School of Medicine.

\section{Availability of data and materials}

The data that support the findings of this study are available from the Utah Population Database but restrictions apply to the availability of these data, which were used under University of Utah IRB and the Utah Resource for Genetic and Epidemiologic Research (RGE) approval, and so are not publicly available. Data are however available from the authors upon reasonable request and with permission of the Utah Resource for Genetic and Epidemiologic Research (RGE) and University of Utah IRB.

\section{Authors' contributions}

All authors have read and approved the final manuscript. DA made sizeable contributions to the acquisition of data, data analysis, and was a major contributor in writing the manuscript. LCA made valuable contributions to the conception and design of this study, acquisition of data, data analysis, and was a major contributor in writing the manuscript. AC made substantial contributions to conception and design of this study, acquisition of data and analysis, and was a major contributor in writing the manuscript. HC contributed to the conception and design of this study and participated in writing the manuscript. SH made significant contributions in the design of this study, acquisition of data, data analysis and visualization, and was a major contributor in writing the manuscript. RJ generously contributed to the acquisition of data, data analysis and visualization, and was a major contributor in writing the manuscript. WK made large contributions to data analysis, data visualization, and was a major contributor in writing the manuscript. TK genotyped patient samples, assisted in interpretation of patient allele status, and was a contributor in writing the manuscript. JS performed histological examinations of glioma samples and was a contributor in writing the manuscript. CP performed histological examinations of glioma samples and was a contributor in writing the manuscript.

\section{Ethics approval and consent to participate}

The Utah Resource for Genetic and Epidemiologic Research (RGE), and the University of Utah (UofU) Institutional Review Board (IRB) approved access to the Utah Population Database for this study. The RGE reviews all papers prior to publication to ensure confidentiality of UPDB participants. The population of this study was derived from the Huntsman Cancer Institute Cancer Clinical Research Database (CCR). Secondary analyses of patient data and specimens with a waiver of informed consent were approved by the University of Utah IRB and all research was conducted following the international standards set forth in the Declaration of Helsinki. Stored germline tissues, somatic tissues, or DNA was obtained from the Huntsman Cancer Institute Biorepository.

\section{Consent for publication}

Not applicable.

\section{Competing interests}

The authors declare that they have no competing interests.

\section{Publisher's Note}

Springer Nature remains neutral with regard to jurisdictional claims in published maps and institutional affiliations.

\section{Author details}

${ }^{1}$ George E. Wahlen Department of Veterans Affairs Medical Center, Salt Lake City, Utah, USA. ${ }^{2}$ Division of Genetic Epidemiology, Department of Internal Medicine, University of Utah School of Medicine, Salt Lake City, Utah, USA. ${ }^{3}$ Division of Oncology, University of Utah School of Medicine, Huntsman Cancer Institute, Salt Lake City, Utah, USA. ${ }^{4}$ Department of Neurosurgery, University of Utah School of Medicine, Huntsman Cancer Institute, Salt Lake City, Utah, USA. ${ }^{5}$ Department of Human Genetics/Pediatric Division of Medical Genetics, Graduate Program in Genetic Counseling, University of Utah School of Medicine, 15 North 2030 East, Salt Lake City 84112, Utah, 
USA. ${ }^{6}$ The Mayo Clinic, Department of Laboratory Medicine and Pathology, Rochester, Minnesota, USA. ${ }^{7}$ Department of Population Sciences, University of Utah School of Medicine, Huntsman Cancer Institute, Salt Lake City, Utah, USA. ${ }^{8}$ Division of Anatomic Pathology, University of Utah School of Medicine, Salt Lake City, Utah, USA.

Received: 27 March 2018 Accepted: 19 February 2019

Published online: 01 March 2019

\section{References}

1. Kurian AW, Hare EE, Mills MA, Kingham KE, McPherson L, Whittemore AS, et al. Clinical evaluation of a multiple-gene sequencing panel for hereditary Cancer risk assessment. J Clin Oncol. 2014. https://doi.org/10.1200/JCO.2013.53.6607.

2. Hegde M, Ferber M, Mao R, Samowitz W, Ganguly A. ACMG technical standards and guidelines for genetic testing for inherited colorectal cancer (lynch syndrome, familial adenomatous polyposis, and MYH-associated polyposis). Gen in Med. 2014. https://doi.org/10.1038/gim.2013.166.

3. Robson ME, Bradbury AR, Arun B, Domchek SM, Ford JM, Hampel HL, et al. American Society of Clinical Oncology policy statement update: genetic and genomic testing for cancer susceptibility. J Clin Oncol. 2015. https://doi.org/ 10.1200/JCO.2015.63.0996.

4. Cohen AL, Holmen SL, Colman H. IDH1 and IDH2 mutations in gliomas. Curr Neurol Neurosci Rep. 2013. https://doi.org/10.1007/s11910-013-0345-4.

5. Eckel-Passow JE, Lachance DH, Molinaro AM, et al. Glioma groups based on 1p/19q, IDH, and TERT promoter mutations in tumors. New Engl J Med. 2015. https://doi.org/10.1056/NEJMoa1407279.

6. Louis DN, Perny A, Reifenberger G, von Deimling A, Figarella-Branger D, Cavenee WK, Ohgaki H, Wiestler OD, Kleihues P, Ellison DW. The 2016 World Health Organization classification of tumors of the central nervous system: a summary. Acta Neuropathol. 2016. https://doi.org/10.1007/s00401-016-1545-1.

7. Claus EB, Walsh KM, Wiencke JK, Molinaro AM, Wiemels JL, Schildkraut JM, et al. Survival and low-grade glioma: the emergence of genetic information. Neurosurg Focus. 2014. https://doi.org/10.3171/2014.10.FOCUS12367.

8. Ostrom QT, Bauchet L, Davis FG, Deltour I, Fisher JL, Langer CE, et al. The epidemiology of glioma in adults: a state of the science review. NeuroOncology. 2014. https://doi.org/10.1093/neuonc/nou087.

9. Yan H, Parsons DW, Jin G, McLendon R, Rasheed BA, Yuan W, et al. IDH1 and IDH2 mutations in gliomas. N Engl J Med. 2009. https://doi.org/10.1056/ NEJMoa0808710.

10. Labussière M, Idbaih A, Wang XW, Marie Y, Boisselier B, Falet C, et al. All the 1p19q codeleted gliomas are mutated on IDH1 or IDH2. Neurology. 2010. https://doi.org/10.1212/WNL.0b013e3181e1cf3a.

11. Blumenthal DT, Cannon-Albright LA. Familiality in brain tumors. Neurology. 2008. https://doi.org/10.1212/01.wnl.0000326597.60605.27.

12. Hemminki K, Tretli S, Sundquist J, Johannesen TB, Granstrom C. Familial risks in nervous-system tumours: a histology-specific analysis from Sweden and Norway. Lancet Oncol. 2009. https://doi.org/10.1016/S1470-2045(09)70076-2.

13. Jenkins RB, Xiao Y, Sicotte H, Decker PA, Kollmeyer TM, Hansen HM, et al. A low-frequency variant at 8q24.21 is strongly associated with risk of oligodendroglial tumors and astrocytomas with IDH1 or IDH2 mutation. Nat Genet. 2012. https://doi.org/10.1038/ng.2388.

14. Cohen A, Sato M, Aldape K, Mason CC, Alfaro-Munoz K, Heathcock L, et al. DNA copy number analysis of grade II-III and grade IV gliomas reveals differences in molecular ontogeny including chromothripsis associated with IDH mutation status. Acta Neuropathol Commun. 2015. https://doi.org/10. 1186/s40478-015-0213-3.

15. Enciso-Mora V, Hosking FJ, Kinnersley B, Wang Y, Shete S, Zelenika D, et al. Deciphering the 8q24.21 association for glioma. Hum Mol Genet. 2013. https://doi.org/10.1093/hmg/ddt063.

16. Melin B, Jenkins R. Genetics in glioma: lessons learned from genome-wide association studies. Curr Opin Neurol. 2013. https://doi.org/10.1097/WCO. 0000000000000033.

17. Walsh KM, Anderson E, Hansen HM, Decker PA, Kosel ML, Kollmeyer T, et al. Analysis of 60 reported glioma risk SNPs replicates published GWAS findings but fails to replicate associations from published candidate-gene studies. Genet Epidemiol. 2013. https://doi.org/10.1002/gepi.21707.

18. Rice T, Lachance DH, Molinaro AM, Eckel-Passow JE, Walsh KM, BarnholtzSloan J, et al. Understanding inherited genetic risk of adult glioma-a review. Neuro-Oncol Pract. 2016. https://doi.org/10.1093/nop/npv026.

19. Cannon Albright LA. Utah family-based analysis: past, present and future. Hum Hered. 2008. https://doi.org/10.1159/000112368.
20. Kang MR, Kim MS, Oh JE, Kim YR, Song SY, Seo SI, et al. Mutational analysis of IDH1 codon 132 in glioblastomas and other common cancers. Int J Cancer. 2009. https://doi.org/10.1002/ijc.24379.

21. Teicher BA, Linehan WM, Helman LJ. Targeting cancer metabolism. Clin Cancer Res. 2012. https://doi.org/10.1158/1078-0432.CCR-12-2587.

22. Losman JA, Kaelin WG Jr. What a difference a hydroxyl makes: mutant IDH, (R)-2-Hydroxyglutarate, and Cancer. Genes Dev. 2013. https://doi.org/10. 1101/gad.217406.113.

23. McLellan T, Jorde LB, Skolnick MH. Genetic distances between the Utah Mormons and related populations. Am J Hum Genet. 1984;36:836-57.

24. Woolf CM, Stephens FE, Mulaik DD, Gilbert RE. An investigation of the frequency of consanguineous marriages among the Mormons and their relatives in the United States. Am J Hum Genet. 1956;8:236-52.

25. Albright F, Teerlink C, Werner TL, Cannon-Albright LA. Significant evidence for a heritable contribution to cancer predisposition: a review of cancer familiality by site. BMC Cancer. 2012. https://doi.org/10.1186/1471-2407-12-138.

26. Haiman CA, Patterson N, Freedman ML, Myers SR, Pike MC, Waliszewska A, et al. Multiple regions within $8 \mathrm{q} 24$ independently affect risk for prostate cancer. Nat Genet. 2007. https://doi.org/10.1038/ng2015.

27. Ghoussaini M, Song H, Koessler T, Al Olama AA, Kote-Jarai Z, Driver KE, et al. Multiple loci with different cancer specificities within the 8q24 gene desert. J Natl Cancer Inst. 2008. https://doi.org/10.1093/jnci/djn190.

28. Zanke BW, Greenwood CM, Rangrej J, Kustra R, Tenesa A, Farrington SM, et al. Genome-wide association scan identifies a colorectal cancer susceptibility locus on chromosome 8q24. Nat Genet. 2007. https://doi.org/ 10.1038/ng2089.

29. Ahmadiyeh N, Pomerantz MM, Grisanzio C, Herman P, Jia L, Almendro V, et al. 8 q24 prostate, breast, and colon cancer risk loci show tissue-specific long-range interaction with MYC. Proc Natl Acad Sci U S A. 2010. https:// doi.org/10.1073/pnas.0910668107.

30. Gudmundsson J, Sulem P, Gudbjartsson DF, Masson G, Agnarsson BA, Benediktsdottir KR, et al. A study based on whole-genome sequencing yields a rare variant at $8 \mathrm{q} 24$ associated with prostate cancer. Nat Genet. 2012. https://doi.org/10.1038/ng.2437.

31. Jin Y, Desta Z, Stearns V, Ward B, Ho H, Lee KH, et al. CYP2D6 genotype, antidepressant use, and tamoxifen metabolism during adjuvant breast cancer treatment. J Natl Cancer Inst. 2005. https://doi.org/10.1093/jnci/dji005.

32. Oktay Y, Ülgen OCE, Akyerli CB, Yüksel S, Erdemgil Y, Durası IM, et al. IDHmutant glioma specific association of rs55705857 located at 8q24.21 involves MYC deregulation. Sci Rep. 2016. https://doi.org/10.1038/srep27569.

33. Jenkins RB, Wrensch MR, Johnson D, Fridley BL, Decker PA, Xiao Y, et al. Distinct germ line polymorphisms underlie glioma morphologic heterogeneity. Cancer Genet. 2011. https://doi.org/10.1016/j.cancergencyto.2010.10.002.

34. Shete S, Lau CC, Houlston RS, Claus EB, Barnholtz-Sloan J, Lai R, et al. Genome-wide high-density SNP linkage search for glioma susceptibility loci: results from the Gliogene consortium. Cancer Res 2011. doi: https://doi.org/ 10.1158/0008-5472.CAN-11-0013.

Ready to submit your research? Choose BMC and benefit from:

- fast, convenient online submission

- thorough peer review by experienced researchers in your field

- rapid publication on acceptance

- support for research data, including large and complex data types

- gold Open Access which fosters wider collaboration and increased citations

- maximum visibility for your research: over $100 \mathrm{M}$ website views per year

At $\mathrm{BMC}$, research is always in progress.

Learn more biomedcentral.com/submissions 